\title{
Advancing Health Policy and Advocacy Education in Medical School through a Student-run Elective
}

\author{
Michael J. Luke \\ Donald and Barbara Zucker School of Medicine at Hofstra/Northwell, michaelluke3@gmail.com
}

Sara J. Abrahams

Donald and Barbara Zucker School of Medicine at Hofstra/Northwell, sabrahams1@pride.hofstra.edu

Danielle Llanos

Donald and Barbara Zucker School of Medicine at Hofstra/Northwell, dllanos1@pride.hofstra.edu

Danielle A. L. Howell

Donald and Barbara Zucker School of Medicine at Hofstra/Northwell, dhowell1@pride.hofstra.edu

\section{Lauren Block}

Donald and Barbara Zucker School of Medicine at Hofstra/Northwell, Iblock2@northwell.edu

Cooper Rowan Medical Journal: https://rdw.rowan.edu/crjcsm

Would you like to be a reviewer? Please fill in this short form to express your interest.

\section{Recommended Citation}

Luke, Michael J.; Abrahams, Sara J.; Llanos, Danielle; Howell, Danielle A. L.; and Block, Lauren (2020) "Advancing Health Policy and Advocacy Education in Medical School through a Student-run Elective," Cooper Rowan Medical Journal: Vol. 2 : Iss. 1 , Article 1.

DOI: 10.31986/issn.2578-3343_vol1iss2.1

Available at: https://rdw.rowan.edu/crjcsm/vol2/iss1/1

\section{(c) (i)}

This work is licensed under a Creative Commons Attribution 4.0 License.

This Medical Education is brought to you for free and open access by the Rowan University Journals at Rowan Digital Works. It has been accepted for inclusion in Cooper Rowan Medical Journal by an authorized editor of Rowan Digital Works. For more information, please contact brush@rowan.edu. 
Advancing Health Policy and Advocacy Education in Medical School through a Student-run Elective 


\title{
Advancing Health Policy and Advocacy Education in Medical School through a Student-run Elective
}

\section{Michael Luke MD ${ }^{1 *}$, Sara Abrahams BA², Danielle Llanos BA ${ }^{2}$, Danielle Howell $\mathrm{BA}^{2}$ \& Lauren Block MD, MPH ${ }^{2}$}

${ }^{1}$ Department of Pediatrics, Donald and Barbara Zucker School of Medicine at Hofstra/Northwell, 500 Hofstra Blvd., Hempstead, NY

${ }^{2}$ Donald and Barbara Zucker School of Medicine at Hofstra/Northwell, 500 Hofstra Blvd., Hempstead, NY *Corresponding author: michaelluke.pediatrics@gmail.com (Michael Luke)

\begin{abstract}
Introduction

Training medical students in the policy topics of healthcare economics, delivery systems, disparities, and reform helps to prepare them for the growing role of advocacy in medicine. We used a near-peer educational model, in which students teach peers of differing academic years, to create an elective to advance learners' policy knowledge and advocacy skills, while simultaneously offering student directors hands-on experience in educational program development.
\end{abstract}

\section{Methods}

The 4-week elective for fourth year medical students included weekly readings, policy seminars, advocacy workshops, and journal clubs. Longitudinally, students prepared for a policy debate and prepared a research project or Op-Ed article on a healthcare disparity topic of their choice. The elective was designed, coordinated, and implemented by a team of first, second, third, and fourth-year medical students with faculty adviser oversight. Pre- and post-surveys were utilized to assess student learners' knowledge of subject material and their perceptions of the effectiveness of the curriculum. Student directors self-assessed their confidence with the subject material and acquired skill in educational program development. Surveys are available in the supplementary file associated with this publication.

\section{Results}

Student learners $(n=6)$ noted significant improvement in their knowledge of health policy $(\mathrm{P}=0.0002)$ and advocacy $(\mathrm{P}=0.0064)$. They also reported improvement in several subtopics under policy and advocacy, 
with significant improvements seen in healthcare reform $(\mathrm{P}=0.0131)$ and writing skills $(\mathrm{P}=0.0099)$. Student directors $(n=4)$ reported improved skills in curriculum development, educational evaluation, and leadership.

\section{Discussion}

This novel student-run elective provided effective training in health policy and advocacy that extends beyond traditional curricula in medical school. Employing a near-peer model, the elective offers a sustainable system to educate interested students in these subjects and provide student directors unique experience in medical education. Further evaluation of future iterations will help determine the effectiveness of the curriculum in advancing individual policy and advocacy subtopics to guide future curricular modifications.

\section{INTRODUCTION}

The value of the physician's role in health policy and health advocacy has become more evident as healthcare issues become increasingly debated in the political arena. In this work, we use "health policy" to encompass laws, regulations, and practices of entities that affect health, including but not limited to government. "Health advocacy" generally refers to the act of offering support for a health-related issue, practice, or policy. Earnest et al. highlighted the unique position afforded to medical professionals in this landscape, as we may better understand the medical complexity of issues in health politics, are capable of correlating social factors to health outcomes, and have access to policy makers and public trust amongst citizens. ${ }^{1}$ While physicians overwhelmingly view civic engagement as a tenant of medical professionalism ${ }^{2,3}$ and multiple physician organizations have declared advocacy as core to their mission, ${ }^{4-7}$ most physicians do not engage in advocacy. ${ }^{8,9}$ While many explanations have been postulated as to why, ${ }^{1}$ one factor may be insufficient exposure in medical training. Several institutions have begun to develop curricula in these fields, but they have focused primarily on public health, ${ }^{10}$ community health, ${ }^{11,12}$ activism research, ${ }^{13}$ or the social determinants of health. ${ }^{14,15}$

While there has been increasing acceptance that policy and advocacy education should be available for medical students there continues to be controversy over whether this education should be mandatory or optional. Huddle argues that medicine should not require a political stance from its members, and thus advocacy training should not take away from medical school's primary mission - research and education. ${ }^{16}$ However, some educational bodies have disagreed and incorporated mandatory policy or advocacy education into their curricula, ${ }^{17}$ including all ACGME-accredited pediatric residencies. ${ }^{6}$

Todd et al., purports that medical school may be an opportune avenue to begin this education, as values and attitudes are most malleable at this time. Several authors have shared the anticipated benefits of 
incorporating policy and advocacy into undergraduate medical education, including understanding medical professionalism and public health, ${ }^{17}$ navigating medical decision making, ${ }^{18}$ promoting cost consciousness, ${ }^{19}$ and reducing physician burnout. ${ }^{20}$ Medical deans rated health policy and politics as significant subject areas to include in undergraduate medical education in a 1999 survey. ${ }^{21}$ However, data since has shown that students lack knowledge of foundational topics, such as medical economics and health care systems. ${ }^{18,22-24}$ This suggests there is administrative support as well as a need for more formalized education in health policy and advocacy.

One of the largest expected barriers to creating and sustaining policy or advocacy curricula in undergraduate medical education is that many medical schools do not employ scholars in these fields for the explicit role of educating students on these topics. ${ }^{18}$ In recent years, an increasingly popular method of alleviating faculty teaching burden in medical education has been peer teaching. Peer teaching has been rapidly adopted to free up educational resources and help student teachers better consolidate knowledge and prepare for their future roles as clinician educators. It also offers student learners role models and non-threatening learning environments. ${ }^{25,26}$

A peer teaching model is an educational strategy where students of the same academic level teach each other to facilitate group learning. Similarly, a near-peer teaching model is one where students are responsible for providing or facilitating education for peers of different academic years, more traditionally their junior students. A study on student perceptions on the near-peer teaching dynamics suggested that more acceptable roles for near-peer teachers include information provider, role model, and facilitator, while planner and resource developer were considered to be less suitable roles. ${ }^{27}$ However, Peluso et al., suggests that designing an elective provides a platform for experimentation and innovation in addition to challenging students to create methods of sustainability. ${ }^{28}$

Employing a near-peer model, we developed an elective that offered a sustainable system to educate interested students in health policy and provide student directors unique experience in providing medical education.

\section{METHODS}

\section{Curricular Design}

Prior to the design of the elective, a literature review of existing published curricula on topics related to policy and advocacy was performed. Preliminary policy topics were selected from proposed curricular components by Patel et al. ${ }^{18}$ Campos-Outcalt,,${ }^{10}$ Riegelman, ${ }^{23}$ and Mou et al.${ }^{30}$ Policy and advocacy experts in the Northwell Health system were then interviewed as an initial needs assessment to determine what health policy and advocacy topics would be most beneficial for medical students with no prior 
knowledge of the subjects. Based on this input, a final roster of topics focusing on healthcare economics, healthcare disparities, healthcare delivery systems, and healthcare reform was selected.

Health Policy \& Advocacy Curriculum

The four-week health policy and advocacy course is a pass/fail elective offered annually to fourth year medical students enrolled at the Donald and Barbara Zucker School of Medicine at Hofstra/Northwell. Students enrolled in the elective are referred to as 'learners.' The elective includes: 12 didactic policy seminars; 12 interactive advocacy workshops; and 4 student-led journal clubs. Each week includes readings, seminars, and workshops related to a central theme with class time ranging from 10-20 hours per week. The policy seminars are one- or two-hour sessions led by content experts from the health system, medical school, or community. They provide foundational knowledge in various health policy topics related to the weekly themes through discussions, case studies, and lectures. The advocacy workshops are skill-based sessions led by content experts and provide student learners with opportunities to hone skills in Op-Ed writing, debate, advocating locally, and resolution writing over a one-hour period. Each seminar and advocacy workshop is attended by the student learners and a content expert serving as facilitator, while the journal clubs consist of only student learners and one or two student directors. While not required, student directors are allowed to attend any of the policy seminars that do not conflict with other academic requirements, such as class or clinical rotations. Learning objectives for each session were developed by the student directors in conjunction with the content expert facilitating each particular session. The structure of policy seminars is a combination of didactics and group discussion framed by the learning objectives and readings. The advocacy workshops consist of the student learners practicing a specific skill, such as Op-Ed writing, with the guidance of facilitators. Weekly, hour-long journal clubs serve as capstone sessions to tie the prior sessions to the weekly theme as well as debrief with student directors to obtain informal feedback on each session and the week as a whole. As special features, students involved in the elective are permitted to audit classes at the School of Public Health at Hofstra University, attend events at Northwell Health's Health Policy Week, participate in a political debate against residents of Northwell Health's Internal Medicine program, and attend a two-day visit to the State Legislature in Albany, New York. See Table 1 in the Appendix for an overall layout of the curriculum. Titles and learning objectives for each individual seminar, workshop, and journal club can be found in Table 4 in the Appendix. In addition to the pass/fail grade, student learners were provided with narrative feedback from the faculty adviser with input from content experts who served as session facilitators.

The elective was held in 2018 and 2019 with two cohorts of three learners each; for a total of 6 learners between the two years. The first iteration of the elective held in 2018 involved a longitudinal advocacy project, where students selected research mentors prior to the start of the elective and were required to 
present their independent work at the end of their four-week experience. Based on feedback from 2018 learners, the longitudinal initiative in the elective was modified in 2019 through the addition of an Op-Ed piece examining an aspect of healthcare disparities of the learners' choosing in place of the longitudinal advocacy project. With the exception of this change, the structure of the elective remained the same over its two iterations.

\section{Team Structure}

The elective was designed, coordinated, and executed by a team comprised of a first, second, third, and fourth-year medical student, with faculty oversight, to establish a sustainable lineage for future leadership and appropriately delineate tasks based on academic schedules. Students chosen to design and coordinate the elective are referred to as 'directors.' Each year, a new director was selected from the first-year medical student class based on submitted paragraphs of interest and qualifications reviewed by senior directors. Desired qualifications, include a passion for policy and advocacy and any program or project development experience.

The team structure (Figure 1) was employed to best organize responsibilities and maximize experiential learning. With this system in place, first-year directors select articles, formulate discussion questions, and assist with the facilitation of journal clubs. This allows them to focus on familiarizing themselves with the topic material for the course in order to transition smoothly into the second-year role. With this foundational knowledge of the course structure and content, second-year students stepped into the primary role of session director responsible for communication between session facilitators, student learners, and student directors as well as logistical planning for sessions. This included finalizing the learning objectives for each session with facilitators, reserving meeting space, and sending reminders to all participants. Third-year directors transitioned into the team manager role, which included sending weekly overview emails to student learners with the week's events and serving as the primary resource for the first-and second-year student directors, hereby developing essential leadership skills with the support of the fourth-year director. Fourth-year directors' leadership experience and content expertise enabled them to oversee the three more junior directors as well as pursue quality improvement and scholarly initiatives to further the elective as a whole. Note that while fourth-year directors have the opportunity to enroll in the elective and participate as a learner, this has not occurred. The faculty adviser served as a supervisor, a source of feedback, and a mentor for scholarly endeavors. 


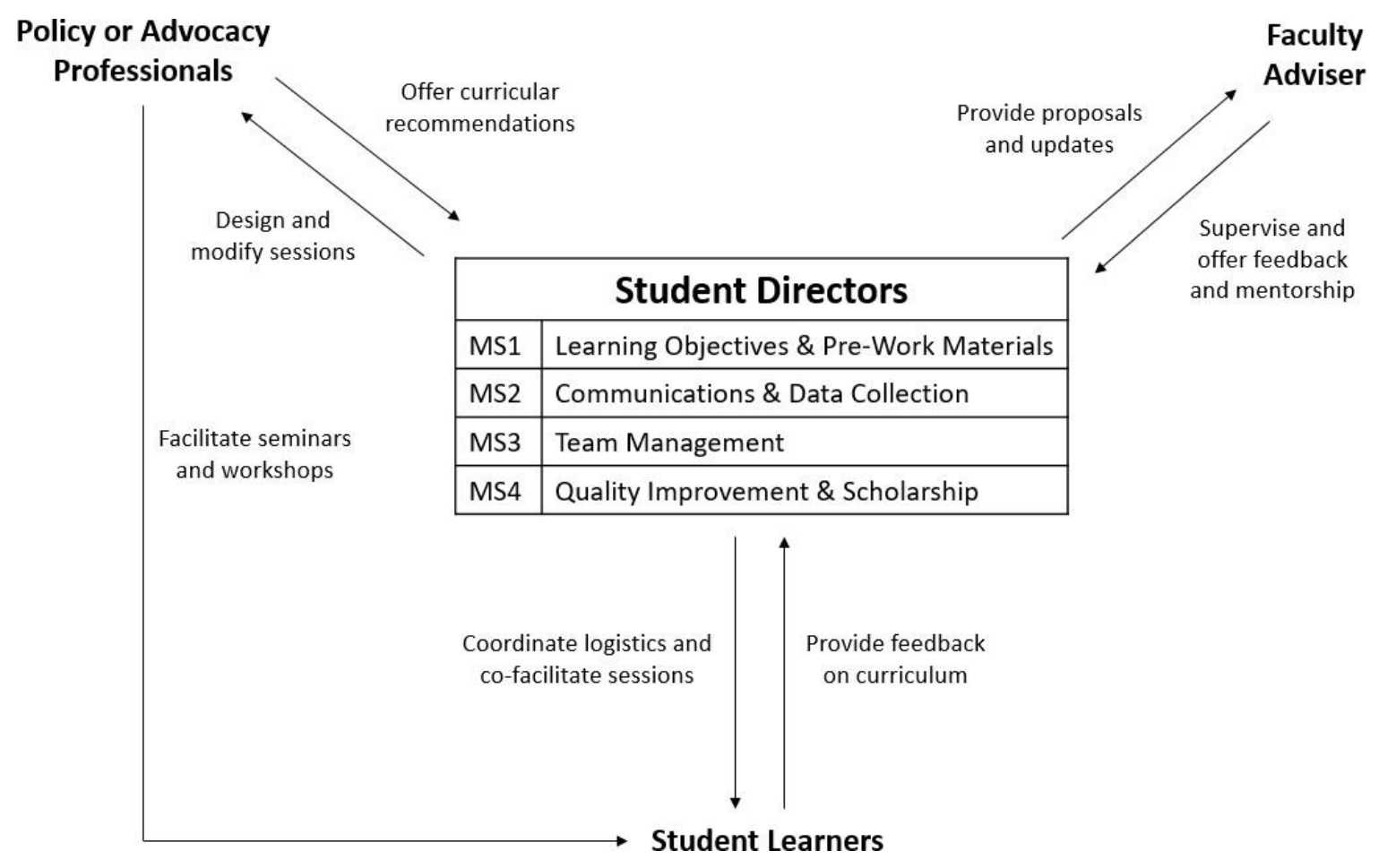

Figure 1 Team structure, flow, and definition of roles for the development and coordination of the elective.

\section{Evaluation}

This curriculum was evaluated using novel, non-validated surveys, which included quantitative and qualitative elements. Surveys were created to reflect the primary learning objectives of the elective as well as the impact of student direction. Student learners completed pre-surveys with Likert scores to assess their baseline knowledge of health policy and health advocacy at the start of the course (supplementary materials). During the second iteration of the course, additional sub-topics were assessed. At the end of their experience, student learners completed a post-survey with Likert scores to reassess their knowledge of these areas (supplementary materials). These surveys also assessed their perception of the organization and effectiveness of the student-run curriculum with a final focus on learner satisfaction with the overall curriculum. Student directors also completed a survey following the second iteration of the elective to assess changes in their knowledge of health policy, health advocacy, and educational program development, as well as their perceptions of the efficacy of the near-peer educational model. Analysis

An independent statistical review was performed to determine the optimal method of statistical analysis for this data set. Pre- and post-curriculum survey responses were examined using paired t-test analysis. A thematic analysis was performed by three independent reviewers to evaluate for themes in our qualitative data. 


\section{RESULTS}

From 2018 to 2019, six student learners and four student directors participated in our study. All ten participants were full-time students at the Donald and Barbara Zucker School of Medicine at Hofstra/Northwell in New York. All learners were studying in their fourth year, while directors spanned the full four years of medical school. Four out of six learners reported receiving some formal training in either health policy or health advocacy in the past. All but one expressed an interest in pursuing a formal degree in these subjects in the future. None of our student directors had received formal training in these subjects, while all but one expressed an interest in pursuing a master's degree in health policy.

Learner and director knowledge

All six student learners completed the pre- and post-elective surveys and all four student directors completed the director-specific survey. Analysis of pre- and post-curriculum data for all six student learners reported a statistically significant improvement $(\mathrm{p}<0.01)$ in knowledge of both health policy and health advocacy, see Table 2 in the Appendix. While not achieving statistical significance, knowledge in healthcare structure and paper writing (both $\mathrm{p}<0.10)$ demonstrated a trend towards statistical significance. Student directors self-assessed their own improvement in knowledge of health policy and health advocacy through their participation as student directors, which was captured in the postcurriculum survey Table 2.

Results of student learners' reported improved knowledge of subtopics in health policy and advocacy can be found in Table 3 in the Appendix. Pre- and post-elective data is available for 2019 learners, which is accompanied by post-curriculum results from learners in 2018 and directors in 2019. Statistically significant improvements $(\mathrm{p}<0.05)$ were noted in healthcare reform and writing skills related to policy and advocacy. Director satisfaction All four student directors reported improved skills in curriculum development, educational evaluation, and leadership as a result of their involvement in this elective. Two directors noted a marked improvement in their knowledge of medical education, while two noted a moderate improvement.

Learner satisfaction

In assessing learner satisfaction of the course, four out of six of the learners noted the organization and communication during the course was better than other electives, while two out of six identified them as comparable. All of the learners reported that they would strongly recommend the elective. Four out of six rated the elective as excellent in quality, with two rating it as very good.

Qualitative data

Thematic analysis of qualitative data suggested several themes related to the benefits and challenges 
involved in this elective. Nearly all student learners commented on the unique opportunity to meet with a wide variety of professionals in the fields of health policy and health advocacy. Additionally, the next most common themes among learners were an appreciation of the organization of the elective and that the course offered a unique education not traditionally offered in medical education. This near-peer model also allowed student learners and student directors to learn from one another's knowledge and experience. More than half of the student directors noted that the most valuable experience in participating in the elective was gaining experience in curricular design and being able to share student perspectives on these subjects. Additionally, half of the directors appreciated the increased exposure to the content material and improved communication skills. Half of the directors also noted that one of the greatest challenges as a director is the inability to participate in all of the student learners' sessions. Student directors did not believe there was a profound issue in designing and coordinating an elective for their peers, as the seniority in medical education does not equate to greater knowledge in policy or advocacy. On the contrary, half suggested that their student perspective made it easier to create a relevant and approachable curriculum for other students.

\section{DISCUSSION}

Our health policy and advocacy elective has been developed, designed, and coordinated by medical students. The goal of the elective is to build foundational knowledge in health policy and to develop skills in order to apply that knowledge to the advocacy arena. In this curriculum, near-peer teachers serve as information providers, facilitators, planners, and resource developers filling a previously unmet educational need. For peer learners, this model was designed on the principle of cognitive congruence, ${ }^{29}$ to offer them a comfortable learning environment where new material is presented at an appropriate and digestible level. For peer directors, this model offers the traditional near-peer teaching benefit of enhancing knowledge of the subject matter as well as hands-on experience in the design, development, and coordination of medical education programming.

Our curriculum offered a combination of policy seminars, advocacy workshops, and student-led journal clubs to provide students with an immersive experience in these fields. This innovative model was found to produce a significant improvement in students' knowledge of health policy and advocacy over two years through a near-peer initiated and managed program. This was likely a result of multiple novel attributes of our curriculum.

Our seminars and recommended readings provided students with foundational knowledge in the policy topics of healthcare economics and healthcare delivery systems, while the workshops aimed to build skills to apply this knowledge towards advocacy efforts in healthcare disparities and healthcare reform. Such a curriculum addresses the curricular changes demanded by several scholars in medical education over the 
years. ${ }^{17,18,24,30,31}$ To date, while some published curricula address topics related to these fields, ${ }^{10,11,13-15,23,32}$ we have identified no published studies evaluating curriculum focused primarily on health policy and health advocacy in the current literature.

The elective capitalized on the interdisciplinary nature of healthcare policy by allowing our students to learn from content experts in different facets of the field. Based on the qualitative analysis, what students found most valuable about the elective experience was the opportunity to meet with and learn from such a large variety of experienced policy and advocacy professionals. The emphasis on interprofessional and interdisciplinary education in medicine has grown in recent years. Current literature has primarily focused on the benefits of physicians working alongside other providers (nurses, physician assistants, etc.) to provide better individual care, ${ }^{33,34}$ but this could possibly be adapted to suggest that better training alongside policy and advocacy professionals could provide better system-wide care.

Our student-led model offers a sustainable method of educating students on these subjects at an appropriate level for their introductory learning, without increasing the teaching- or coordination-burden on core faculty. The majority of student learners identified the organization and communication involved in our elective as better than other electives. As most fourth-year electives are coordinated by clinical physicians, having this elective operated by multiple medical students likely allowed for consistent and dedicated communication with the student learners. Moreover, qualitative responses from directors indicated that students offered a unique opportunity to create a relevant and approachable curriculum. The near-peer model allows student directors to also gain exposure to our content material. All student directors noted an improved knowledge of health policy and health advocacy, as a result of their participation in the elective. Qualitative responses suggest that this is likely due to the opportunity to learn from their peers during debriefs and sessions they co-facilitate. However, the most commonly identified challenge as a student director was not participating in the elective itself as a learner. This likely made it difficult to fully appreciate the content material presented to the student learners by the policy and advocacy professionals and subsequently develop a commanding knowledge of the subjects. There is no literature available on peer teaching surrounding these subjects in medical education, and further evaluation is necessary to determine if our model truly produces a significant improvement in the policy or advocacy knowledge of student directors.

Serving as a director offers students a unique opportunity to get hands-on experience in medical education. Reported skill improvements in curriculum development, educational evaluation, and leadership support the hypothesis suggested by Peluso et al., that coordinating an elective can serve as a profound learning opportunity for medical students. ${ }^{28}$ Moreover, while there is ample literature on the benefits of near-peer models where peers serve as educators, ${ }^{25-27}$ future research should focus on the efficacy of models where peers serve as educational program developers. 
The strengths of this study include perspectives from multiple stakeholders, as both student learners and student directors self-assessed their knowledge and skills, and the ability to assess the course qualitatively through weekly debrief sessions and quantitatively through formal surveys.

Limitations of this study, include a single institution, small sample size, lack of control group, and reliance on students' perceptions of knowledge. Given the small number of participants and near-peer nature of the study, there was also likely a component of response bias, as survey participants may have been reluctant to offer critical reviews of their peers. As this is an optional elective, participation is geared towards students with an inherent interest in the subject matter. Therefore, the favorable responses to the curriculum may not be reproducible in a setting where this curriculum is mandatory for all students.

Future efforts by the team focus on sample size expansion, greater objective data collection, and continued assessment and modification of the curriculum. Subsequent iterations of the elective will continue to be evaluated to determine the effectiveness of the curriculum in teaching subtopics under policy and advocacy and to guide curricular changes moving forward.

\section{References}

1. Earnest MA, Wong SL, Federico SG. Perspective: Physician Advocacy: What Is It and How Do We Do It? Acad Med. 2010;85(1):63-67. doi:10.1097/ACM.0b013e3181c40d40

2. Campbell EG, Regan S, Gruen RL, et al. Professionalism in medicine: results of a national survey of physicians. Ann Intern Med. 2007;147(11):795-802. http://www.ncbi.nlm.nih.gov/pubmed/18056665. Accessed February 25, 2019.

3. Gruen RL, Campbell EG, Blumenthal D. Public roles of US physicians: Community participation, political involvement, and collective advocacy. J Am Med Assoc. 2006;296(20):2467-2475. doi:10.1001/jama.296.20.2467

4. Physicians AC of. ACP Ethics Manual Sixth Edition | Medical Ethics Resource | ACP. https://www.acponline.org/clinical-information/ethics-and-professionalism/acp-ethics-manualseventh-edition-a-comprehensive-medical-ethics-resource. Published 2012. Accessed February 25, 2019.

5. $\quad$ Future of Family Medicine Project 1.0 -- Programs \&amp; Initiatives. https://www.aafp.org/about/initiatives/future-family-medicine/ffm.html. Accessed February 25, 2019.

6. ACGME Program Requirements for Graduate Medical Education in Pediatrics ACGME Program Requirements for Graduate Medical Education in Pediatrics Common Program Requirements Are in BOLD.; 2017.

https://www.acgme.org/Portals/0/PFAssets/ProgramRequirements/320_pediatrics_2017-07-01.pdf.

Accessed February 25, 2019. 
7. American Medical Association. Declaration of Professional Responsibility: Medicine's Social Contract with Humanity. Mo Med. 2002;99(5):195. http://www.ncbi.nlm.nih.gov/pubmed/12025762. Accessed February 25, 2019.

8. Rothman DJ. Medical Professionalism — Focusing on the Real Issues. N Engl J Med. 2000;342(17):1284-1286. doi:10.1056/NEJM200004273421711

9. Landers SH, Sehgal AR. Health care lobbying in the United States. Am J Med. 2004;116(7):474-477. doi:10.1016/j.amjmed.2003.10.037

10. Campos-Outcalt D. The integration of public health and prevention into all years of a medical school curriculum. Am J Prev Med. 2011;41(4 SUPPL. 3):S306-S308. doi:10.1016/j.amepre.2011.06.012

11. McIntosh S, Block RC, Kapsak G, Pearson TA. Training medical students in community health: A novel required fourth-year clerkship at the University of Rochester. Acad Med. 2008;83(4):357-364. doi:10.1097/ACM.0b013e3181668410

12. Belkowitz J, Sanders LM, Zhang C, et al. Teaching health advocacy to medical students: A comparison study. J Public Heal Manag Pract. 2014;20(6):E10-E19. doi:10.1097/PHH.0000000000000031

13. Cha SS, Ross JS, Lurie P, Sacajiu G. Description of a research-based health activism curriculum for medical students. J Gen Intern Med. 2006;21(12):1325-1328. doi:10.1111/j.1525-1497.2006.00608.x

14. Song A, of Medicine Committee on the Social Determinants of Health BC of MC on the SD of, Poythress E, Bocchini C, Kass J. Reorienting Orientation: Introducing the Social Determinants of Health to First-Year Medical StudentsAngela. MedEdPORTAL. 2018;14(14). doi:10.15766/mep_2374-8265.10752

15. McDonald M, West J, Israel T. From Identification to Advocacy: A Module for Teaching Social Determinants of Health. MedEdPORTAL Publ. 2015;(11). doi:10.15766/mep_2374-8265.10266

16. Huddle TS. Perspective: Medical Professionalism and Medical Education Should Not Involve Commitments to Political Advocacy. Acad Med. 2011;86(3):378-383. doi:10.1097/ACM.0b013e3182086efe

17. Croft D, Jay SJ, Meslin EM, Gaffney MM, Odell JD. Perspective: Is it time for advocacy training in medical education? Acad Med. 2012;87(9):1165-1170. doi:10.1097/ACM.0b013e31826232bc

18. Patel MS, Davis MM, Lypson ML. Advancing Medical Education by Teaching Health Policy. N Engl J Med. 2011;364(8):695-697. doi:10.1056/NEJMp1009202

19. Cooke M. Cost Consciousness in Patient Care — What Is Medical Education's Responsibility? N Engl J Med. 2010;362(14):1253-1255. doi:10.1056/NEJMp0911502

20. Eisenstein L. To Fight Burnout, Organize. N Engl J Med. 2018;379(6):509-511. doi:10.1056/NEJMp1803771

21. Patel K. Physicians for the 21St Century: Challenges Facing Medical Education in the United States. 
Eval Health Prof. 2003;22(3):379-398. doi:10.1177/01632789922034374

22. Patel MS, Lypson ML, Davis MM. Medical Student Perceptions of Education in Health Care Systems. Acad Med. 2009;84(9):1301-1306. doi:10.1097/ACM.0b013e3181b17e3e

23. Riegelman R. Commentary: Health systems and health policy: A curriculum for all medical students. Acad Med. 2006;81(4):391-392. doi:10.1097/00001888-200604000-00014

24. Agrawal JR, Huebner J, Hedgecock J, Sehgal AR, Jung P, Simon SR. Medical students' knowledge of the U.S. health care system and their preferences for curricular change: a national survey. Acad Med. 2005;80(5):484-488. http://www.ncbi.nlm.nih.gov/pubmed/15851463. Accessed February 25, 2019.

25. Ten Cate O, Durning S. Peer teaching in medical education: twelve reasons to move from theory to practice. Med Teach. 2007;29(6):591-599. doi:10.1080/01421590701606799

26. Nelson AJ, Nelson S V., Linn AMJ, Raw LE, Kildea HB, Tonkin AL. Tomorrow's educators ... today? Implementing near-peer teaching for medical students. Med Teach. 2013;35(2):156-159. doi:10.3109/0142159X.2012.737961

27. Bulte C, Betts A, Garner K, Durning S. Student teaching: views of student near-peer teachers and learners. Med Teach. 2007;29(6):583-590. doi:10.1080/01421590701583824

28. Peluso MJ, Hafler JP. Medical students as medical educators: opportunities for skill development in the absence of formal training programs. Yale J Biol Med. 2011;84(3):203-209. http://www.ncbi.nlm.nih.gov/pubmed/21966037. Accessed February 25, 2019.

29. Ten Cate O Ten, Durning S. Dimensions and psychology of peer teaching in medical education. Med Teach. 2007;29(6):546-552. doi:10.1080/01421590701583816

30. Mou D, Sarma A, Sethi R, Merryman R. The State of Health Policy Education in U.S. Medical Schools. N Engl J Med. 2011;364(10):e19. doi:10.1056/NEJMp1101603

31. Todd JS. Health Care Reform and the Medical Education Imperative. JAMA J Am Med Assoc. 1992;268(9):1133. doi:10.1001/jama.1992.03490090079018

32. Belkowitz J, Sanders LM, Zhang C, et al. Teaching health advocacy to medical students: A comparison study. J Public Heal Manag Pract. 2014;20(6):E10-E19. doi:10.1097/PHH.0000000000000031

33. Newhouse RP, Spring B. Interdisciplinary evidence-based practice: Moving from silos to synergy. Nurs Outlook. 2010;58(6):309-317. doi:10.1016/j.outlook.2010.09.001

34. Zanotti R, Sartor G, Canova C. Effectiveness of interprofessional education by on-field training for medical students, with a pre-post design. BMC Med Educ. 2015;15(1):121. doi:10.1186/s12909-015040 
Luke et al.: Student-run Health Policy and Advocacy Elective

\section{LIST OF FIGURES}

1 Teamstructure, flow, and definition of roles for the development and coordination of the elective. 
Policy or Advocacy

Professionals

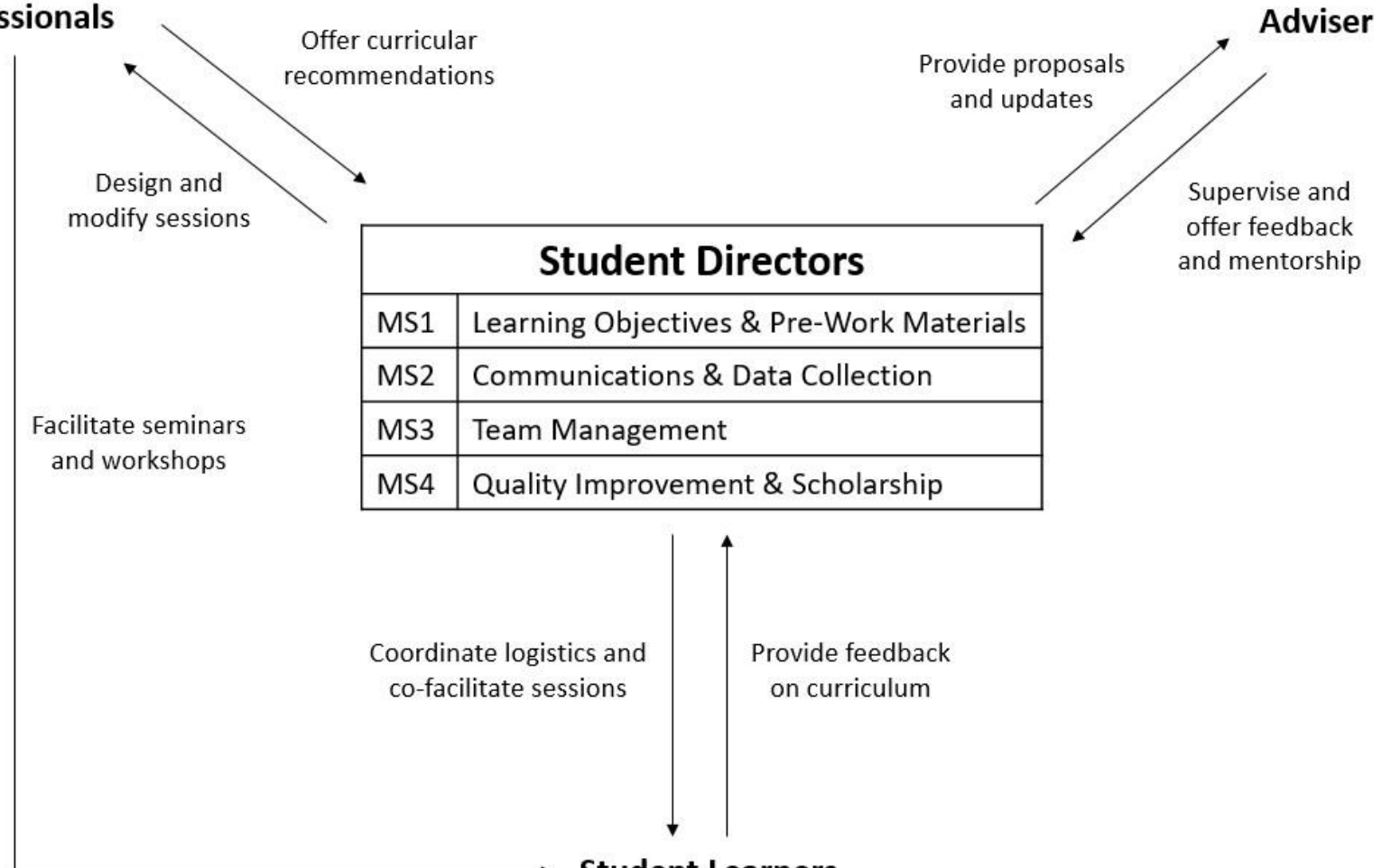

Student Learners

Figure 1 Teamstructure, flow, and definition of roles for the development and coordination of the elective. 


\section{LIST OF TABLES}

1 Sample schedule for the 4-week elective based upon the weekly themes.

2 Pre- and post-survey results showing a statistically significant improvement in Health Policy and Health Advocacy knowledge. Likert score is out of ten. Percentages represent percentage of affirmative responses reporting subjective improvement among directors.

3 Pre-and post-survey results showing a statistically significant improvement in some subtopics of Health Policy and Health Advocacy knowledge. Likert score is out of ten. Percentages represent percentage of affirmative responses reporting subjective improvement for the given student sub-group. 
Table 1 Sample schedule for the 4-week elective based upon the weekly themes.

\begin{tabular}{|c|c|c|c|c|c|}
\hline $\begin{array}{l}\text { Weekly } \\
\text { Theme }\end{array}$ & $\mathbf{M}$ & $\mathbf{T}$ & $\mathbf{W}$ & $\mathbf{T}$ & $\mathbf{F}$ \\
\hline $\begin{array}{l}1 \text { Health- } \\
\text { care } \\
\text { Eco- } \\
\text { nomics }\end{array}$ & $\begin{array}{l}\text { Orientation } \\
\text { Pre-Survey }\end{array}$ & $\begin{array}{l}\text { Policy Seminar } \\
\text { Advocacy } \\
\text { Workshop }\end{array}$ & $\begin{array}{l}\text { Policy } \\
\text { Seminar } \\
\text { Advocacy } \\
\text { Workshop }\end{array}$ & $\begin{array}{l}\text { Advocacy } \\
\text { Workshop }\end{array}$ & $\begin{array}{l}\text { Journal Club } \\
\text { Debrief }\end{array}$ \\
\hline $\begin{array}{l}2 \text { Health- } \\
\text { care } \\
\text { Dispari- } \\
\text { ties }\end{array}$ & $\begin{array}{l}\text { Policy Seminar } \\
\text { Advocacy } \\
\text { Workshop }\end{array}$ & $\begin{array}{l}\text { Policy Seminar } \\
\text { Advocacy } \\
\text { Workshop }\end{array}$ & $\begin{array}{l}\text { Policy } \\
\text { Seminar } \\
\text { Advocacy } \\
\text { Workshop }\end{array}$ & $\begin{array}{l}\text { Advocacy } \\
\text { Workshop }\end{array}$ & $\begin{array}{l}\text { Policy } \\
\text { Debate } \\
\text { Journal Club } \\
\text { Debrief }\end{array}$ \\
\hline $\begin{array}{l}3 \text { Health- } \\
\text { care } \\
\text { Delivery }\end{array}$ & Policy Seminar & $\begin{array}{l}\text { Policy Seminar } \\
\text { Advocacy } \\
\text { Workshop }\end{array}$ & $\begin{array}{l}\text { Policy } \\
\text { Seminar } \\
\text { Advocacy } \\
\text { Workshop }\end{array}$ & $\begin{array}{l}\text { Advocacy } \\
\text { Workshop }\end{array}$ & $\begin{array}{l}\text { Journal Club } \\
\text { Debrief }\end{array}$ \\
\hline $\begin{array}{l}4 \text { Health- } \\
\text { care } \\
\text { Reform }\end{array}$ & $\begin{array}{l}\text { State Legislature } \\
\text { Policy Seminar } \\
\text { Policy Seminar }\end{array}$ & $\begin{array}{l}\text { State Legislature } \\
\text { Policy Seminar } \\
\text { Policy Seminar }\end{array}$ & $\begin{array}{l}\text { Advocacy } \\
\text { Workshop }\end{array}$ & $\begin{array}{l}\text { Advocacy } \\
\text { Workshop } \\
\text { Op-Ed } \\
\text { Submission }\end{array}$ & $\begin{array}{l}\text { Journal Club } \\
\text { Debrief } \\
\text { Post-Survey }\end{array}$ \\
\hline
\end{tabular}


Table 2 Pre- and post-survey results showing a statistically significant improvement in Health Policy and Health Advocacy knowledge. Likert score is out of ten. Percentages represent percentage of affirmative responses reporting subjective improvement among directors.

\begin{tabular}{lllll}
\hline Subjects & $\begin{array}{l}\text { Learners Pre-Elective } \\
(\mathbf{n = 6})\end{array}$ & $\begin{array}{l}\text { Learners Post-Elective } \\
(\mathbf{n = 6})\end{array}$ & $\begin{array}{l}\text { P- } \\
\text { Value }\end{array}$ & $\begin{array}{l}\text { Directors } \\
(\mathbf{n}=\mathbf{4})\end{array}$ \\
$\begin{array}{l}\text { Health Policy } \\
\text { Health }\end{array}$ & $4.33 \pm 1.03$ & $8.17 \pm 0.41$ & 0.0002 & $100 \%$ \\
Advocacy & $4.50 \pm 1.76$ & $7.67 \pm 1.03$ & 0.0064 & $100 \%$ \\
& & & & \\
\hline
\end{tabular}


Table 3 Pre- and post-survey results showing a statistically significant improvement in some subtopics of Health Policy and Health Advocacy knowledge. Likert score is out of ten. Percentages represent percentage of affirmative responses reporting subjective improvement for the given student sub-group.

\begin{tabular}{|c|c|c|c|c|}
\hline Subjects & $\begin{array}{l}2019 \text { Learners } \\
\text { Pre-Elective }(n=3)\end{array}$ & $\begin{array}{l}\text { 2019 Learners } \\
\text { Post-Elective }(n=3)\end{array}$ & $\begin{array}{l}\text { P- } 2018 \\
\text { Value Learners }(n= \\
\text { 3) }\end{array}$ & $\begin{array}{l}2019 \\
\text { Directors } \\
(n=4)\end{array}$ \\
\hline $\begin{array}{l}\text { Healthcare } \\
\text { structure }\end{array}$ & $5.67 \pm 1.53$ & $8.3 \pm 0.58$ & $0.0941100 \%$ & $75 \%$ \\
\hline $\begin{array}{l}\text { Healthcare } \\
\text { economics }\end{array}$ & $4.33 \pm 1.52$ & $7.67 \pm 1.15$ & $0.109166 .7 \%$ & $100 \%$ \\
\hline $\begin{array}{l}\text { Healthcare } \\
\text { reform }\end{array}$ & $5.50 \pm 1.32$ & $8.00 \pm 1.00$ & $0.0131100 \%$ & $100 \%$ \\
\hline $\begin{array}{l}\text { Organizing } \\
\text { w/ritins }\end{array}$ & $\begin{array}{l}5.33 \pm 1.15 \\
3.16 \pm 0.29\end{array}$ & $\begin{array}{l}6.67 \pm 0.58 \\
6.50 \pm 0.87\end{array}$ & $\begin{array}{l}0.269733 .3 \% \\
0.0099100 \%\end{array}$ & $\begin{array}{l}100 \% \\
100 \%\end{array}$ \\
\hline $\begin{array}{l}\text { Community } \\
\text { outreach }\end{array}$ & $6.00 \pm 0.00$ & $7.33 \pm 1.15$ & $0.183566 .7 \%$ & $0 \%$ \\
\hline Presenting & $7.67 \pm 0.58$ & $8.00 \pm 1.00$ & $0.741833 .3 \%$ & $75 \%$ \\
\hline Paper writing & $5.33 \pm 1.15$ & $6.67 \pm 0.58$ & $0.057266 .7 \%$ & $100 \%$ \\
\hline $\begin{array}{l}\text { Data } \\
\text { gathering }\end{array}$ & $6.67 \pm 1.15$ & $8.33 \pm 0.58$ & $0.199433 .3 \%$ & $100 \%$ \\
\hline Data analysis & $6.00+1.73$ & $7.67+0.58$ & $0.299966 .7 \%$ & $75 \%$ \\
\hline
\end{tabular}


Table 4 Descriptions of the learning objectives for each Policy Seminar.

\begin{tabular}{ll}
\hline $\begin{array}{l}\text { Policy Seminars } \\
\text { Introduction to }\end{array}$ & $\begin{array}{l}\text { Learning Objectives } \\
\text { Outline the historical antecedents of health insurance and payment reform } \\
\text { Health Policy }\end{array}$ \\
$\begin{array}{l}\text { preceding the ACA. Describe the four dimensions of health policy. Discuss the } \\
\text { role of the physician in health policy. } \\
\text { Contrast the cost of the US Healthcare System to other national models. }\end{array}$ \\
$\begin{array}{l}\text { Structure of } \\
\text { Construct the orbits of US Healthcare System: local, regional, and national. } \\
\text { Politics, Economy, } \\
\text { \& Obamacare }\end{array}$ & $\begin{array}{l}\text { Identify the steps and influencers in policy-making. } \\
\text { Discuss the political factors contributing to the passage of the ACA. Explore the } \\
\text { economic incentives utilized by the ACA to increase participation in the } \\
\text { insurance market. Describe which payers increased their coverage as a result of } \\
\text { the ACA (Medicaid, Medicare, private insurance). }\end{array}$
\end{tabular}

Careers in Policy Identify the trajectory of a career in healthcare policy and advocacy from medical school. Justify the role of healthcare policy and advocacy in different specialties. Describe current initiatives by faculty within healthcare policy and advocacy.

History of Public Explore the history of how the field of public health developed.

Health

Medical-Legal

Partnerships

Patient Centered

Learn about Patient Navigators and their role in the health care team. Learn what a Medical Legal Partnership is and how it works to address Health-Harming Legal Needs. Discuss your role as a physician in advocating for your patients' social needs and helping to address them in the clinical setting.

Medical Homes

Large Healthcare Explore the different models of healthcare delivery. Differentiate Patient Centered Medical Homes, Accountable Care Organizations, MACRA, and DSRIP.

Systems \& Mergers

Understand the advantages and disadvantages of major health system mergers.

State Capital Visit: Identify the parties involved and the considerations taken in the merger. Discuss the impact a merger can have on the health system and healthcare community.

Committee Meeting

State Capital Visit: Learn how to use communication of health policy and management issues using appropriate channels and technologies. Learn about principles of strategic planning and marketing to public health.

Case Discussion Describe a public health problem in terms of magnitude, person, time, and place. State Capital Visit: Quality Improvement Discuss the policy process for improving the health status of populations. Learn to use change management approaches on a large State health initiative. Learn quality and performance improvement concepts to address organizational performance issues.

State Capital Visit:

Clinical Learn the principles of program planning, development, budgeting, Presentation management, and evaluation in organizational and community initiatives. 